\section{Discussion}

Peritonitis was not completely prevented by the Hong Kong connection technique, but the overall rate was low at 0.6 episode/patient year. Analysis of the causes of peritonitis, however, showed that this occurred in seven cases where the technique could not be incriminated (catheter bed fault (two), introduced bacteria (one), modified Travenol technique (three), bowel perforation (one)) and in another four cases where the technique itself led to unexpected damage and subsequent peritonitis directly as a consequence of this damage. It seems reasonable to consider only the compliance problems and the connection failures as being truly representative of the technique, and this gave an overall rate of 0.2 episode/patient year during the study.

Seven modifications were introduced during the study and proved successful, thus confirming the correctness of the original analysis. This was most obvious with catheter faults, catheter bed faults, and dialysis fluid faults. The poor results with the modified Travenol system do not reflect on that system but simply show that the sharp spike of the connecting tubing makes it impossible to use the sterilising bag. Direct contact of stylet with external surface of the sterilising bag was far more hazardous than an open, but no touch, system of connection.

It is impossible to know the exact mechanism of the peritonitis in the three cases considered to be connection failures. Nevertheless, after the introduction of two modifications not a single case of peritonitis attributable to the connection technique occurred in more than 11 patient years, suggesting that the weak points had been identified and corrected.

Only two patients failed to comply, and in each case there were extreme circumstances. In fact, compliance with the technique was remarkably high. This is the more noteworthy when it is appreciated that the patients had little understanding of "germ theory" and Western medicine; were of limited educational standing (two had to be taught to tell the time and eight to write figures); lived in cramped, overcrowded apartments (35 square feet $\left(3.25 \mathrm{~m}^{2}\right)$ is the total space allowance per person) in the housing estates of Hong Kong; and did not receive supervisory visits at home. The technique was in fact quickly learnt and faithfully performed in some 35000 separate connections.

The Hong Kong connection may not be elaborate but it has proved to be effective, simple, cheap, easily learnt, and easily applied. The clear plastic bag allows manipulation visually, provides the enclosed sterile space, and with the chlorhexidine brings about sterilisation both of the air and of the ends of the tubing. This study supports the hypothesis that air contamination is an important cause of peritonitis in continuous ambulatory peritoneal dialysis and that to prevent peritonitis in these patients it is necessary to enclose the connection process with sterilisation of introduced air and tubing ends.

Dr A S P Hua, formerly of the Department of Medicine, University of Hong Kong, conceived both the hypothesis of air contamination and the method of connection.

I thank the nurses of ward 2C, especially Sister J Wong, for their able help and the doctors in the department of medicine for their support.

An illustrated manual on the Hong Kong connection is available on request.

\section{References}

${ }^{1}$ Rasheed A, Goldsmith HJ. Hospital at home, home dialysis. Br $\mathcal{F}$ Hosp Med 1983;29:95-104.

2 Gorey P. An approach to the statistical analysis of peritonitis data from patients on CAPD. Peritoneal Dialysis Bulletin 1981;1:29-32.

${ }^{3}$ Prowant B, Nolph KD. Five years' experience with peritonitis in a CAPD program. Peritoneal Dialysis Bulletin 1982;2:169-70.

4 Gokal R, Ramos JM, Francis DMA, et al. Peritonitis in continuous ambulatory peritoneal dialysis. Lancet 1982 ;ii:1388-91.

${ }^{5}$ Gloor HJ, Nichols WK, Sorkin MI, et al. Peritoneal access and related complications in continuous ambulatory peritoneal dialysis. Am $\mathcal{F} \mathrm{Med}$ 1983;74:593-8.

${ }^{6}$ Rigby RJ, Buttler JL, Petrie JJB. Experience with continuous ambulatory peritoneal dialysis. Med $\mathcal{F}$ Aust $1982 ; \mathrm{i}: 331-5$.

${ }^{7}$ Kincaid-Smith P, Becker G. Continuous ambulatory peritoneal dialysis. Med $\mathcal{F}$ Aust 1982;i:325-6.

(Accepted 25 October 1983)

\title{
Prognosis after myocardial infarction: results of 15 year follow up
}

\author{
MARGARET A MERRILEES, P JOHN SCOTT, ROBIN M NORRIS
}

\begin{abstract}
A total of 271 out of 757 patients who had suffered a myocardial infarction during 1966-7 were still alive after six years; these patients were subsequently followed up 15 years after the infarction. Two hundred and sixty eight $(99 \%)$ of the patients alive at six years and 519 $(95 \%)$ of the 549 originally discharged from hospital were traced. A coronary prognostic index, which had predicted survival both to three years and from three
\end{abstract}

\footnotetext{
Department of Medicine, University of Auckland School of Medicine, Auckland, New Zealand

MARGARET A MERRILEES, BSC, graduate research assistant

P JOHN SCOTT, MD, FRCP, professor and head of department

Coronary Care Unit, Greenlane Hospital, Auckland

ROBIN M NORRIS, MD, FRCP, physician in charge

Correspondence to: Professor P J Scott.
}

to six years after recovery from the infarct also predicted survival from six to 15 years after recovery. The major factor affecting survival to 15 years was age at the time of the original infarct. Among patients aged under 60 at the time of infarction women fared better than men ( $p=0.027)$. Factors in the coronary prognostic index that were associated with impairment of left ventricular function at the time of infarction and that had predicted mortality to three years and from three to six years also predicted mortality from six to 15 years. These factors were cardiac enlargement, pulmonary venous congestion, and the presence of infarction before the index infarct. The dominant cause of death remained coronary heart disease and its complications.

\section{Introduction}

From March 1966 to February 1967, 757 patients with acute myocardial infarction were admitted to the three general 
hospitals in Auckland, New Zealand. Altogether 208 of these patients died, the remaining 549 being discharged from hospital. The fate of these survivors was followed up over the subsequent 15 years until April 1982. Clinical factors observed in these patients at the time of the original admission had previously been correlated with prognosis, both within hospital ${ }^{12}$ and during the first three years ${ }^{3}$ and three to six years after infarction ${ }^{4}$; these factors had been combined to form a coronary prognostic index that predicted survival in hospital ${ }^{2}$ and medium term survival (up to six years). ${ }^{3}{ }^{4}$ The purpose of the present follow up study, from six to 15 years, was to ascertain whether these factors, both separately and combined, could still be used to predict prognosis from six years after the infarct, and to establish whether coronary heart disease remained the leading cause of death in the patients.

\section{Patients and methods}

Clinical data on all patients admitted after myocardial infarction to the three Auckland general hospitals between 1 March 1966 and 28 February 1967 were recorded prospectively at the time of admission. ${ }^{12}$ Follow up in April 1982 was carried out as previously described by correspondence with general practitioners, patients and their relatives, local coroners' offices, and the national registrars of death. ${ }^{3}$ Other information was obtained from the Health Statistics Division, Department of Health, Wellington. Hospital records were consulted and details obtained from death certificates whenever possible. Information from one source was checked against others. For patients who were alive, information was sought concerning whether they were working, were incapacitated, or had retired. For those who had died the mode and circumstances of death were recorded, and whenever possible necropsy information was obtained from hospital or coroners' records.

Survival was calculated by the actuarial method, ${ }^{5}$ the significance of differences in survival curves being calculated with the log rank test. ${ }^{6}$ To establish the significance of differences in mortalities from three to six and from six to 15 years after infarction, the significance levels were recalculated with the survivors at three years and at six years respectively being taken as the populations at risk.

\section{Results}

Of the 271 patients who were known to be alive at the six year follow up, $268(99 \%)$ were traced. Of the 549 who had been discharged from hospital in 1966-7, ${ }^{2} 19$ were lost to follow up during the first three years ${ }^{3}$ and eight over the period to six years. ${ }^{4}$ Thus the total number of patients who could be traced for follow up 15 years after discharge from hospital was $519 / 549(95 \%)$. Of the 268 patients alive at six years who could be traced, $136(51 \%)$ had died by 15 years. Thus of the 519 patients traced 15 years after discharge from hospital after the index infarct, $387(75 \%)$ had died. Hence out of the total of 757 patients who were admitted to hospital with myocardial infarction, 595 died, including those who died in hospital, giving a mortality of $79 \%$. Figure 1 shows the survival curve for the patients who survived to leave hospital.

The table shows the causes of deaths that occurred from six to 15 years of follow up. Ninety nine $(73 \%)$ of the 136 deaths were considered to be cardiac in origin in that they were due to proved or suspected myocardial infarction, sudden death, or cardiac failure. Non-cardiac death was more common among patients aged 70 or over in 1966-7 (13 out of 27 deaths $(48 \%)$ ) than among those who were aged under 50 at that time (three out of 15 deaths $(20 \%)$ ). The proportion of non-cardiac deaths during the follow up from six to 15 years $(27 \%)$ was higher than that during the follow up to three years $(13 \%),{ }^{3}$ and this difference was significant $\left(\chi^{2}\right.$ test, $\left.p=0.0016\right)$.

The group of patients originally discharged from hospital comprised 376 men and 173 women (ratio 2/17:1). After 15 years the survivors comprised 84 men and 48 women (ratio 1.75:1). This difference in ratios was not significant ( $\chi^{2}$ test, $\left.\mathrm{p}=0 \cdot 16\right)$. When men and women aged under 60 at the time of infarction were considered, however, there were 193 men and 57 women in the original cohort (ratio $3 \cdot 39: 1$ ) compared with 64 men and 28 women alive at 15 years (ratio 2.29:1); this difference was significant ( $\chi^{2}$ test, $p=0 \cdot 027$ ).

Figures 2-5 show the effect on survival up to 15 years of the four prognostic factors that formed the basis of the coronary prognostic

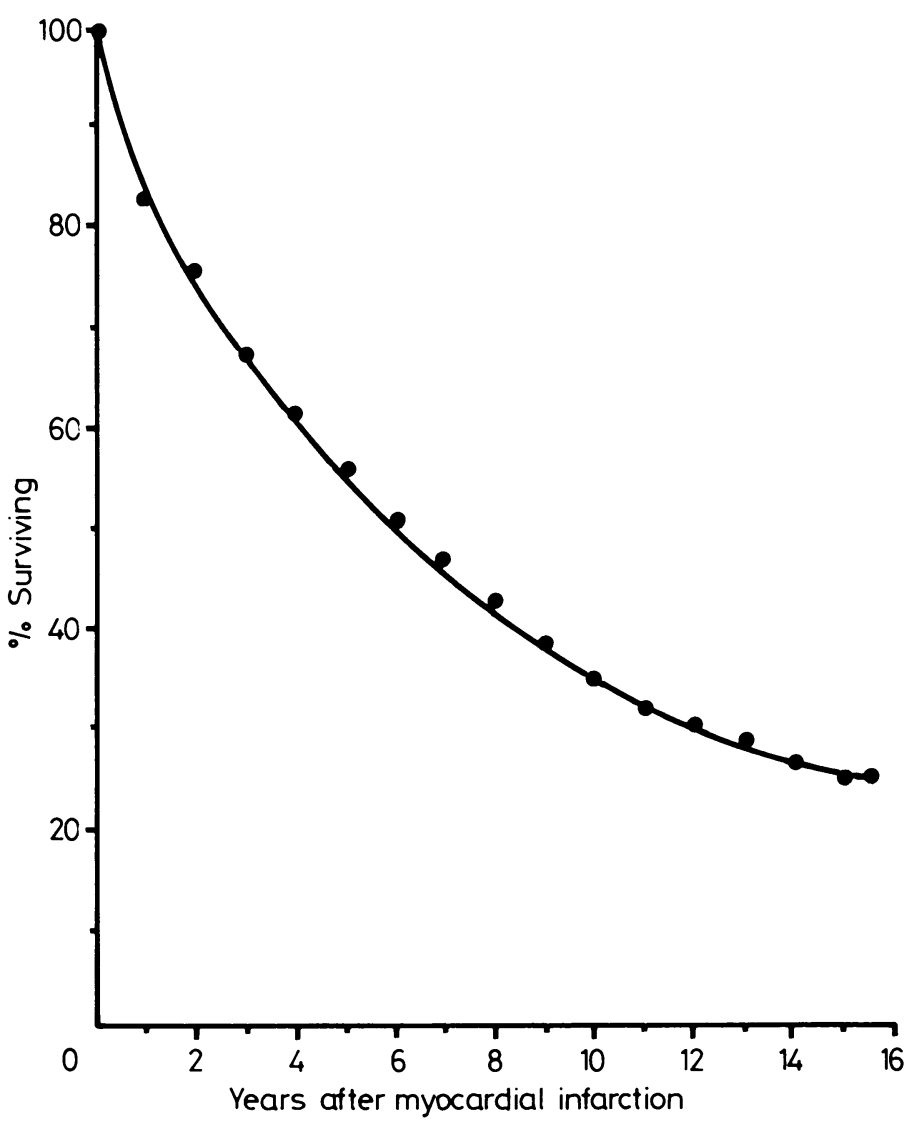

FIG 1-Survival of 530 patients after recovery from myocardial infarction.

Age at time of index myocardial infarction related to cause of death from six to 15 and a half years after infarction

\begin{tabular}{|c|c|c|c|c|c|c|}
\hline \multirow{2}{*}{$\underset{\text { (years) }}{\text { Age }}$} & \multirow{2}{*}{$\begin{array}{l}\text { No } \\
\text { of } \\
\text { cases }\end{array}$} & \multirow{2}{*}{$\begin{array}{c}\text { No }(\%) \\
\text { of } \\
\text { deaths }\end{array}$} & \multicolumn{4}{|c|}{ Cause of death } \\
\hline & & & Cardiac & Cerebrovascular & Cancer & Other \\
\hline $\begin{array}{c}<50 \\
50-59 \\
60-69 \\
70+\end{array}$ & $\begin{array}{l}58 \\
98 \\
79 \\
33\end{array}$ & $\begin{array}{l}15(26) \\
49(50) \\
45(57) \\
27(82)\end{array}$ & $\begin{array}{l}12 \\
39 \\
34 \\
14\end{array}$ & $\begin{array}{l}1 \\
4 \\
2 \\
5\end{array}$ & $\begin{array}{l}1 \\
2 \\
4 \\
1\end{array}$ & $\begin{array}{l}1 \\
4 \\
5 \\
7\end{array}$ \\
\hline Total & 268 & $136(51)$ & 99 & 12 & 8 & 17 \\
\hline
\end{tabular}

index for three year survival ${ }^{3}$-namely, age; presence or absence of cardiac enlargement in the first chest $x$ ray film taken after admission to hospital; presence or absence of pulmonary congestion or oedema in the first chest $x$ ray film; and presence or absence of previous infarction at the time of the index infarction. As expected, age at the time of the index infarction was the most powerful predictor of long term survival. The condition of the heart at the time of infarction, as reflected by the presence or absence of pulmonary venous congestion, pulmonary oedema, or cardiac enlargement, continued to affect prognosis even among those who had already lived for six years after their index infarct. If the index infarction was a recurrence this adversely affected survival mainly for the first three years, though there was still a small effect on mortality from six to 15 years $(p=$ 0.06).

Life tables prepared by the Department of Statistics detail life expectancy for various cohorts of the New Zealand population for the periods $1965-7$ and $1975-7 .^{7}$ Figure 6 shows adapted information from these life tables and contrasts the mortality among our patients with myocardial infarction with that among the general population of New Zealand in broad categories of age. With the exception of our cohort of elderly women, life expectancy is considerably reduced for men and women in New Zealand who suffer a myocardial infarction.

Figure 7 shows mortality for the three periods of follow up according to the score obtained with the coronary prognostic index at the time of the index infarction. The significant increase in mortality with increasing coronary prognostic index noted at the three and six years of follow up was still apparent over the six to 15 year follow 

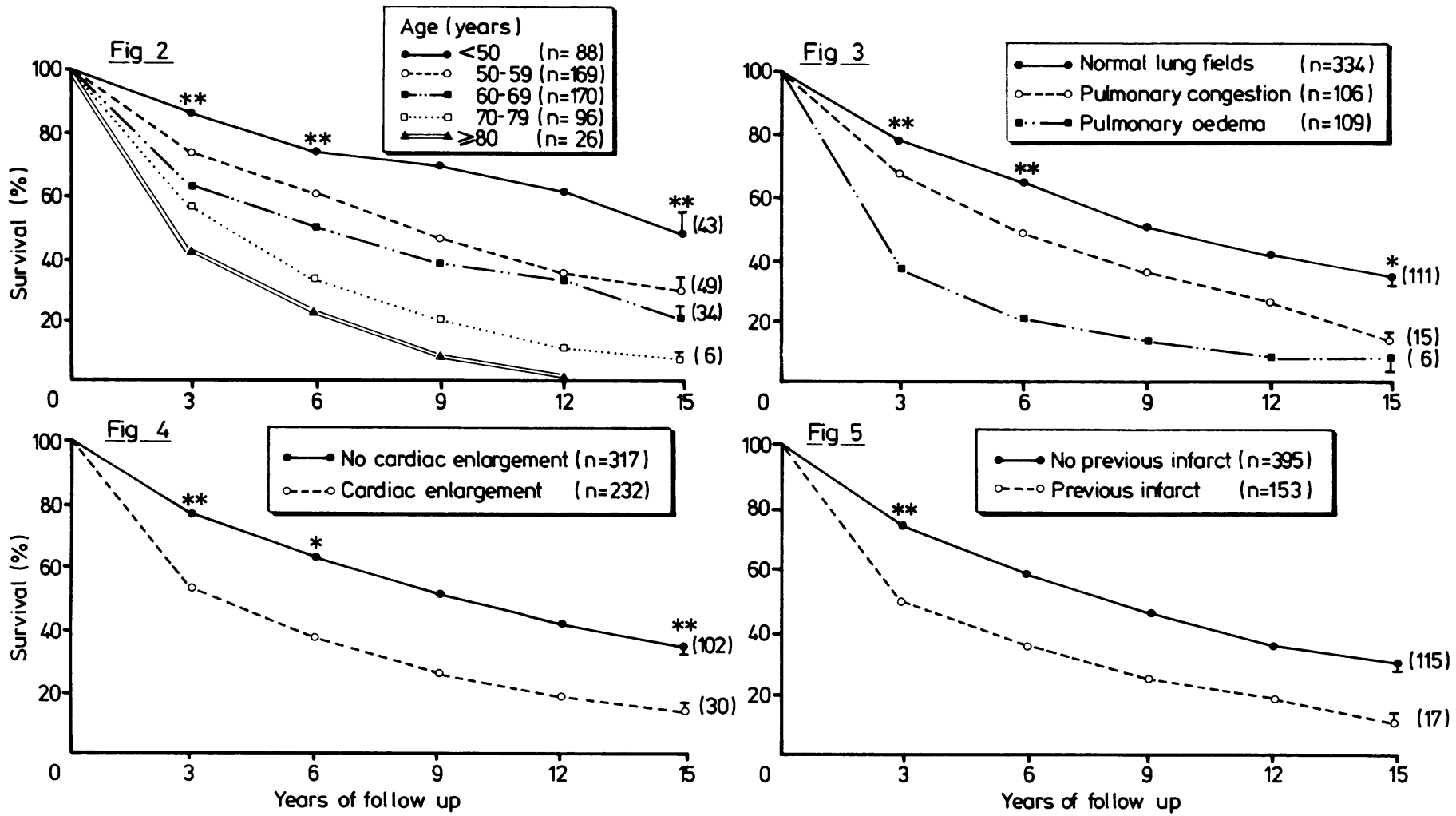

FIG 2-Effect of age at time of index infarct on 15 year survival. Vertical bars indicate SEs of estimates; figures at 15 years indicate numbers of survivors.

Significance of differences among all age groups for survival up to three years, from three to six years, and from six to 15 years: ${ }^{*} p<0.05 ;{ }^{* *} p<0.01$.

FIG 3-Effect of radiological pulmonary venous congestion and pulmonary oedema at time of index infarct on 15 year survival. Vertical bars indicate SEs of estimates; figures at 15 years indicate numbers of survivors.

Significance of differences among all age groups for survival up to three years, from three to six years, and from six to 15 years: ${ }^{*} p<0 \cdot 05 ;{ }^{* *} p<0.01$.

FIG 4-Effect of radiological cardiac enlargement at time of index infarct on 15 year survival. Vertical bars indicate SEs of estimates; figures at 15 years indicate numbers of survivors.

Significance of differences among all age groups for survival up to three years, from three to six years, and from six to 15 years: ${ }^{*} p<0 \cdot 05 ;{ }^{* *} p<0 \cdot 01$.

FIG 5-Effect of previous infarction at time of index infarct on 15 year survival. Vertical bars indicate SEs of estimates; figures at 15 years indicate numbers of survivors. There was no significant difference between the two groups in survival from three to six years; the difference in survival from six to 15 years was marginally significant $(p=0 \cdot 06)$. (Based on 548 patients as information was inadequate in one case.)

up. Mortality six to 15 years after infarction was $36 \%$ among the patients with a coronary prognostic index of $<3 ; 61 \%$ among those with an index of $3-5.9 ; 68 \%$ among those with an index of $6-8.9$; and $74 \%$ among those with an index of $>9$. The difference in mortality from six to 15 years after infarction between patients with an index of $<3$ and those with an index of $\geqslant 3$ was highly significant $\left(\chi^{2}=22 \cdot 0\right.$, $\mathrm{p}<0.0001$ ).

\section{Discussion}

We believe that this is the most complete long term follow up of patients after myocardial infarction so far reported. The 132 patients who were alive at the time of our survey in 1982 were the survivors of a cohort of 757 who had been admitted to hospitals 15-16 years previously. Patients were of all ages, there was no case selection, and we successfully traced $95 \%$ of the patients. The mean follow up period was $15 \frac{1}{2}$ years, but for simplicity we have called this 15 years throughout this paper.

Prognosis six to 15 years after infarction was related mainly to age but was also linked with the severity of cardiac dysfunction as shown by a chest $x$ ray film taken within a few hours after the infarction. Cardiomegaly, pulmonary venous hypertension, and pulmonary oedema in patients with ischaemic heart disease all indicate the degree of left ventricular damage, which may be due either to an evolving infarct or to a previous incident. Infarct size would appear to be the major determinant of long term prognosis for patients with acute myocardial infarction who survive long enough to be admitted to hospital. Thus, if infarct size could be restricted through therapeutic measures introduced soon after the onset of infarction long term prognosis might be considerably improved. ${ }^{8} 9$

During the time since our patients were first studied sophisticated tests of left ventricular function have become available. In particular, left ventricular ejection fraction has been used as an index of survival and has been measured in conjunction with coronary arteriography one to two months after recovery from infarction. ${ }^{10-12}$ These studies have shown that a low ejection fraction $(<40 \%)$ appears to be the most important adverse risk factor for long term survival. A recent study of 325 patients in Auckland (mean follow up three and a half years) confirmed that low ejection fraction rather than severe coronary artery disease is the most important angiographically determinable risk factor. ${ }^{13}$ Interestingly, however, multivariate analysis of the data on these patients showed that the coronary prognostic index was at least as reliable as the ejection fraction in predicting the risk of late death.

The prognosis for patients with a low coronary prognostic index is not good when compared with that of subjects of similar age in the general population. Information from the life tables used to prepare figure 6 showed a predicted 15 year survival greater than $90 \%$ for subjects aged $40-49,75-80 \%$ for those aged $50-59,50-55 \%$ for those aged $60-69$, and $10-12 \%$ for those aged 70-79. ${ }^{7}$ Comparison of these figures for the general population of New Zealand with those for our patients with myocardial infarction shows the high rate of attrition that occurs after recovery from myocardial infarction. 
Predicted survival, total New Zealand population 1965-7

Predicted survival, total New Zealand population 1975-7

Observed survival, patients with myocardial infarction
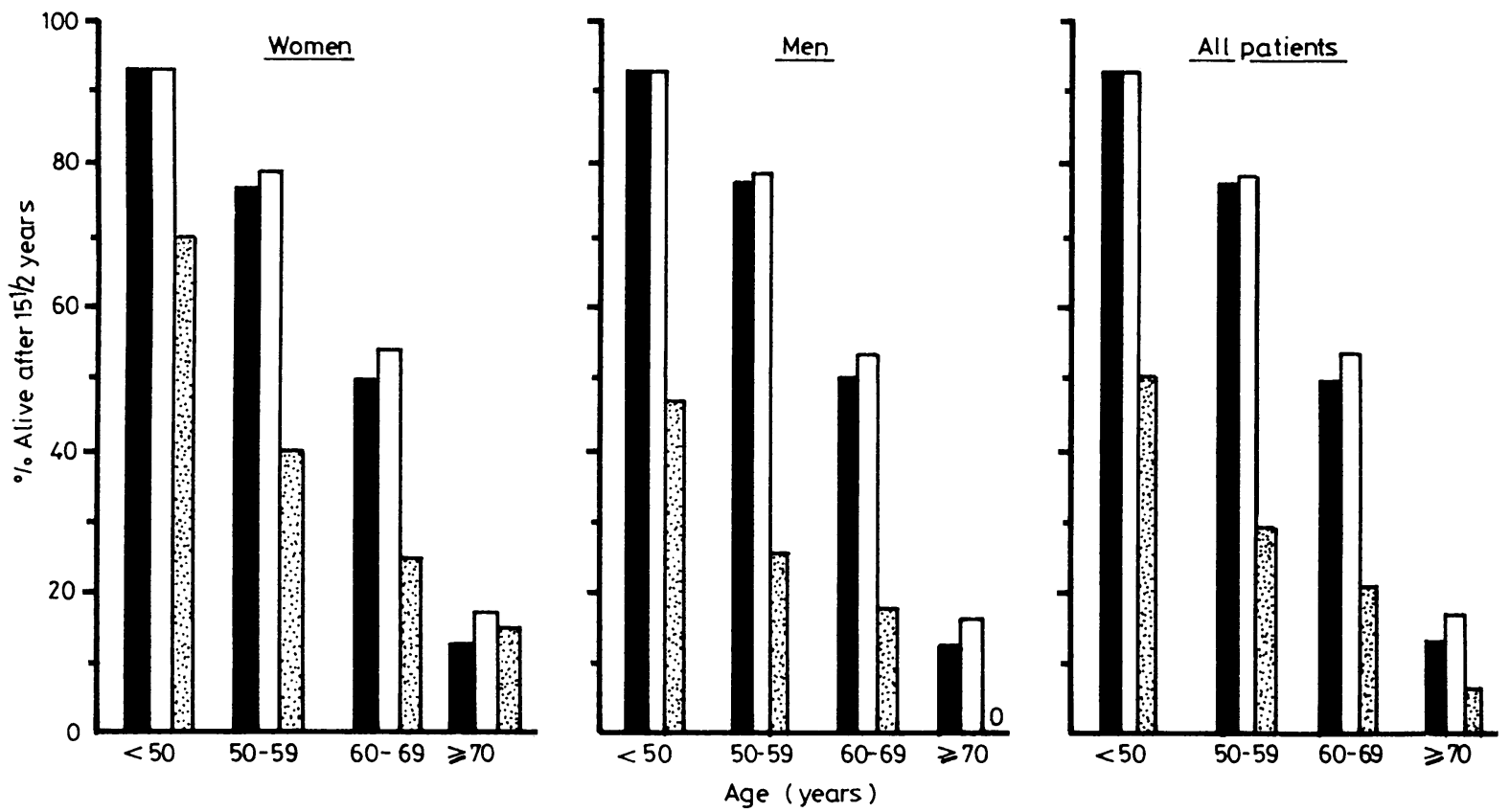

FIG 6-Survival of patients with myocardial infarction in four age categories compared with predicted survival of general population of New Zealand.

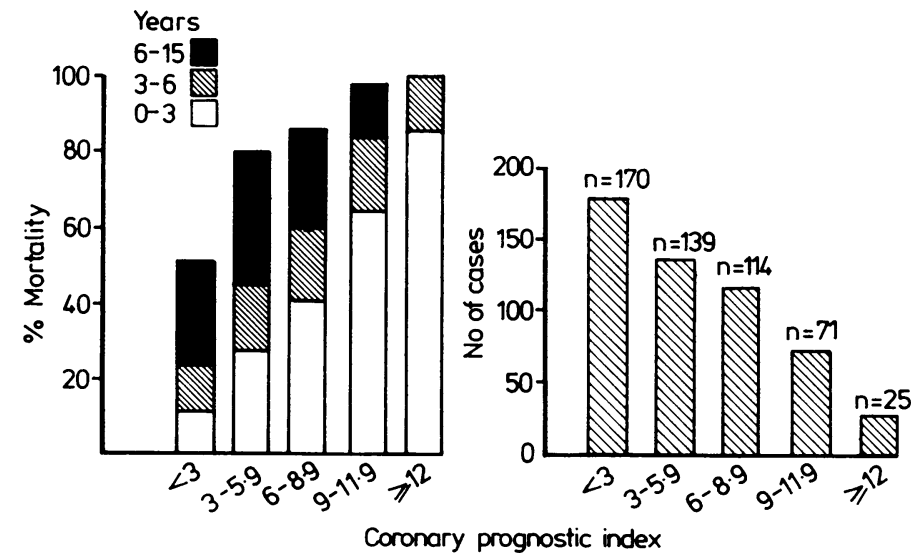

FIG 7-Number of patients and percentage mortality in groups with an increasingly poor prognosis as assessed by the long term coronary prognostic index.

We are grateful to Mrs B Tacon for secretarial help and to Dr A Stewart and Dr R Whitlock for advice and help on statistical methods. MAM was funded by a grant from the Medical Research Council of New Zealand.

\section{References}

1 Norris RM, Bensley KE, Caughey DE, Scott PJ. Hospital mortality in acute myocardial infarction. $\mathrm{Br} M e d \mathcal{F} 1968$;ii: $143-6$.

2 Norris RM, Brandt PWT, Caughey DE, Lee AJ, Scott PJ. A new coronary prognostic index. Lancet $1969 ; \mathrm{i}: 274-8$.

${ }^{3}$ Norris RM, Caughey DE, Deeming LW, Mercer CJ, Scott JP. Coronary prognostic index for predicting survival after recovery from acute myocardial infarction. Lancet $1970 ; \mathrm{ii}: 485-8$.

${ }^{4}$ Norris RM, Caughey DE, Mercer CJ, Scott PJ. Prognosis after myocardial infarction: six-year follow-up. Br Heart $\mathcal{f} 1974$;36:786-90.

- Berkson J, Gage RP. Calculation of survival rates for cancer. Mayo Clin Proc 1950;25:270.
${ }^{6}$ Peto R, Pike MC, Armitage $\mathrm{P}$, et al. Design and analysis of randomized clinical trials requiring prolonged observation of each patient. II Analysis and examples. $B r f$ Cancer $1977 ; 35: 1-39$.

${ }^{7}$ Government Statistician of New Zealand. New Zealand life tables: 1965-67, 1970-72, 1975-77. Wellington, New Zealand: Government Printing Office, 1969, 1975, 1079.

${ }^{8}$ Rude RE, Muller JE, Brauwald D. Efforts to limit the size of myocardial infarcts. Ann Intern Med $1981 ; 95: 736-61$.

${ }^{9}$ Rentrop P. Mortality and functional changes after intracoronary streptokinase infusion. Circulation $1982 ; 66$,suppl II :335.

10 Taylor GJ, Humphries JO, Mellits ED, et al. Predictors of clinical course, coronary anatomy and left ventricular function after recovery from acute myocardial infarction. Circulation 1980;62:960-70.

11 Sanz G, Castaner A, Betriu A, et al. Determinants of prognosis in survivors of myocardial infarction. A prospective clinical angiographic study. N Engl f Med 1982;306:1064-70.

${ }^{12}$ De Feyter PJ, va Eenige MJ, Dighton DH, Visser FC, de Jong J, Roos JP. Prognostic value of exercise testing, coronary angiography and left ventriculography 6-8 weeks after myocardial infarction. Circulation $1982 ; 66: 725-36$.

${ }^{13}$ Norris RM, Barnaby PF, Brandt PWT, et al. Prognosis after recovery from first myocardial infarction: determinants of reinfarction and sudden death. $A m \mathcal{F}$ Cardiol 1984 (in press).

(Accepted 1 November 1983)

THE FACE, AND ITS INFIRMITIES-It is palpable, that the cause of redness and breaking out of the face, is a venomous matter, or filthy vapours ascending from the stomach towards the head; where meeting with a rheum or flegm thence descending, mix with it, and break out in the face. Therefore let the first intention of cure to be cleanse the stomach. Let such as are troubled with red faces, abstain from salt meats, salt fish and herrings, drinking of strong beer, strong waters or Wine, Garlick, Onions, and Mustard. For a face full of red pimples-Dissolve Camphire in Vinegar, and mix it, and the Vinegar with Celandine-water, and wash the face with it: this cured a maid in twenty days, that had been troubled with the infirmity half so many years. To take away the marks of the small pox-Take the juice of Fennel, heat it lukewarm, and when the small Pox are well scabbed, anoint the face with it divers times in a day, three or four days together. (Nicholas Culpeper (1616-54) The Complete Herbal, 1850.) 